\title{
Endoscopic removal of a 35-mm fish bone totally embedded in the gastric wall
}

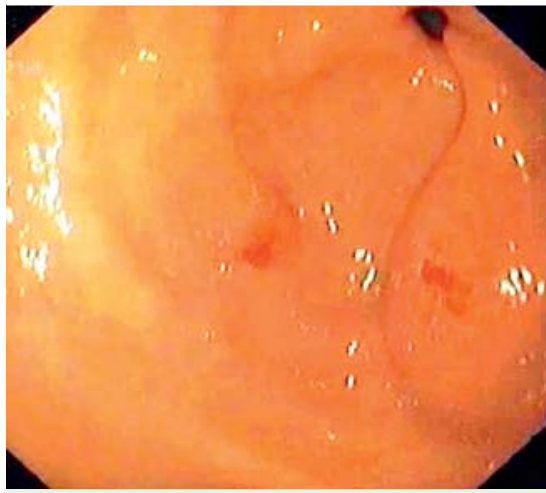

Fig. 1 A 12-mm subepithelial bulge in the gastric antrum covered with congested mucosa.

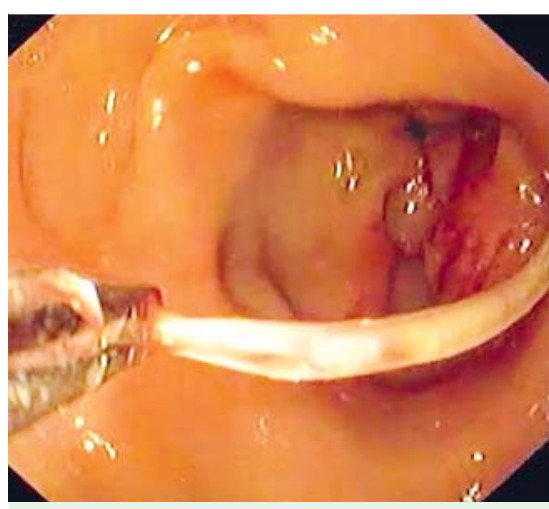

Fig. 3 Removal of the fish bone using alligator forceps.

A 61-year-old woman with no relevant medical history attended the emergency department with a 3-day history of epigastric pain and fever, and reports of fish bone ingestion 6 days earlier. No signs of peritoneal irritation were found during abdominal examination. The patient underwent an abdominal computed tomography scan, which revealed a gastric wall thickening with a radiodense linear foreign body embedded in the wall, associated with mesenteric stranding but no free air. Upper endoscopy was performed and showed a 12-mm subepithelial bulge covered with congested mucosa in the gastric antrum ( $\bullet$ Fig. 1). Using a biopsy forceps, multiple biopsies were taken from the overlying mucosa, exposing the tip of the foreign body ( $\bullet$ Fig. 2 ).

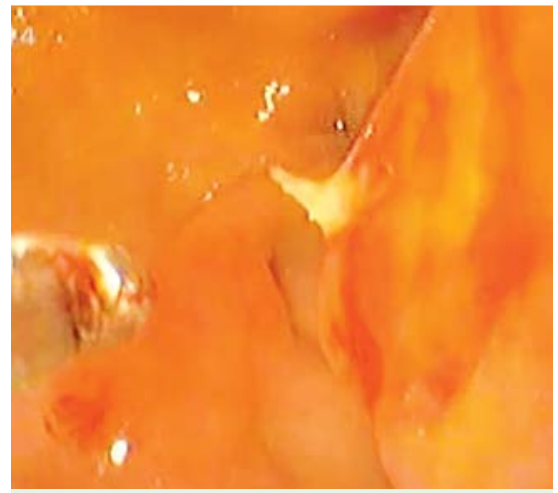

Fig. 2 The tip of the fish bone, which was exposed after multiple biopsies.

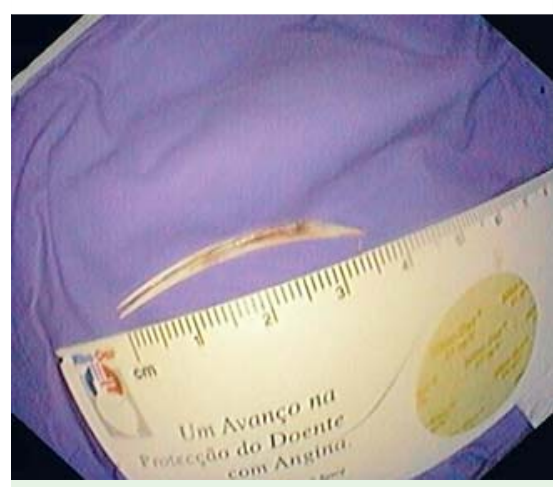

Fig. 4 The 35-mm fish bone after endoscopic removal.

Subsequently, a 35-mm fish bone was safely removed from the gastric wall using an alligator forceps ( Fig.3, $\bullet$ Fig.4). Finally, a through-the-scope clip was placed to close the mucosal injury. The patient was discharged with no further symptoms after 7 days of intravenous antibiotic treatment.

Fish bones embedded in the gastric wall leading to subepithelial bulging and mimicking a subepithelial lesion are rare, despite fish bones being the most frequently ingested foreign body that causes gastrointestinal tract perforation [1]. In this setting, the diagnosis has been mainly achieved only after surgical resection of the pseudotumoral lesions [2]. Endoscopic removal of fish bones that cause transmural perforation with no overt

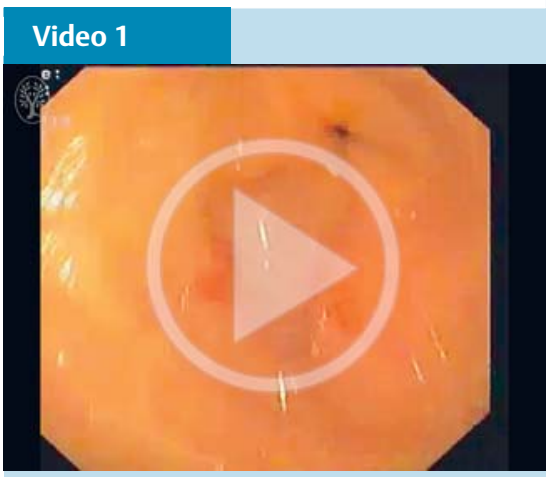

Endoscopic removal of a 35-mm fish bone that was totally embedded in the gastric wall.

peritonitis has been reported [3]. Indeed, in the course of an endoscopic ultrasound (EUS)-guided drainage of a gastric wall abscess, a 25-mm piece of wooden skewer was successfully removed by endoscopy after being unexpectedly exposed [4]. In the present case, the endoscopic and CT scan findings allowed us to identify the most likely location of the foreign body and, subsequently, to remove it. To our knowledge, this is the first report of endoscopic removal without EUS guidance of a foreign body that was totally embedded in the gastric wall.

Endoscopy_UCTN_Code_TTT_1AO_2AL

\section{Competing interests: None}

\section{José Rodrigues, Pedro Barreiro, Liliana Carvalho, Maria Ana Túlio, Cristina Chagas}

Serviço de Gastrenterologia, Centro Hospitalar de Lisboa Ocidental, Lisboa, Portugal

\section{References}

1 Shan GD, Chen ZP, Xu YS et al. Gastric foreign body granuloma caused by an embedded fishbone: a case report. World J Gastroenterol 2014; 20: 3388 - 3390

2 Kim SW, Kim SW, Song SK. Gastric pseudotumoral lesion caused by a fish bone mimicking a gastric submucosal tumor. J Gastric Cancer 2014; 14: 204-206 
3 Nastaskin IJ, Ransibrahmanakul K, Trudeau $W$. Transmural perforation of the stomach by a fishbone. Clin Gastroenterol Hepatol 2008; 6: A26

4 Katsinelos $P$, Chatzimavroudis $G$, Zavos $C$ et al. A pyogenous gastric abscess that developed following ingestion of a piece of a wooden skewer: successful treatment with endoscopic incision. J Gastrointestin Liver Dis 2007; 16: $113-115$

\section{Bibliography}

DOI http://dx.doi.org/

10.1055/s-0042-104653

Endoscopy 2016; 48: E131-E132

(C) Georg Thieme Verlag KG

Stuttgart · New York

ISSN 0013-726X
Corresponding author

José Rodrigues, MD

Serviço de Gastrenterologia

Centro Hospitalar de Lisboa Ocidental -

Hospital de Egas Moniz

Rua da Junqueira 126

1349-019, Lisboa

Portugal

Fax: +351-21-0432430

jp.azevedo.rodrigues@gmail.com 